\title{
Preservation of musical memory in Alzheimer's disease
}

\author{
HOWARD A CRYSTAL, ELLEN GROBER, DAVID MASUR
}

\author{
From the Department of Neurology, Albert Einstein College of Medicine, Yeshiva University, New York, United \\ States
}

SUMMARY An 82 year old musician with Alzheimer's disease (AD) showed a preserved ability to play previously learned piano compositions from memory while being unable to identify the composer or titles of each work. He also showed a preserved ability to learn the new skill of mirror reading while being unable to recall or recognise new information. Both anterograde and retrograde procedural memory may be relatively spared in AD.

Recent investigations of memory functioning in both normal and amnesic subjects distinguish between procedural memory or information based on skills learned implicitly and without awareness, and declarative memory or information based on specific facts acquired explicitly and with deliberate intention. Studies have shown that procedural and declarative memories are not uniformly impaired in subjects with neurological disease. Amnesic subjects with Korsakoff's syndrome demonstrated normal learning of the skills required to read reversed mirror print, despite profound amnesia for the words they had read and for the details of the test.' Previous studies documented preservation of anterograde procedural memory shown by the ability to acquire new skills. We report the preservation of retrograde procedural memory in a patient with Alzheimer's disease who despite severe impairment in declarative memory showed intact ability to play previously learned piano compositions from memory.

At the age of 77 , this subject volunteered to participate in a longitudinal study of risk factors for dementia and was tested annually for the next seven years. He started to complain of memory problems two years before entry into the study.

\section{Case report}

The subject was a musicologist with over 12 years of formal musical training who had worked for over 40 years as a music editor. Throughout his adult life he had practised the piano two hours a day. Concerned about instructing his children in music, he made his family listen to classical music every evening during dinner, and quizzed his children on the composer of each composition.

Correspondence to: Dr Howard Crystal, Department of Neurology, Albert Einstein College of Medicine, Yeshiva University, 1300 Morris Park Avenue, Bronx, NY 10461, United States.

Received 7 February 1989 and in revised form 19 May 1989. Accepted 5 July 1989
His past medical history recorded a head injury with concussion one year before entry into the study. In the fourth year of the study he was involved in a motor vehicle accident with transient alteration in consciousness. CT performed two days after the accident was normal. A family history showed that his father became demented at the age of 70 .

Table 1 summarises his neuropsychological test results in years 1 to 7. When the study began, his score on recall 1 of the Fuld Object Memory Evaluation (FOME) ${ }^{2}$ showed marked impairment in recent verbal memory. (Normal subjects, ages 75-85 score 7-8 items correct on this test). ${ }^{3}$ Impairment in verbal memory was corroborated by his score of $24 / 144$ possible items on a 12-item, 12-trial selective reminding test. $^{45}$ (Normals, ages 75-85, score 100-115, D Masur, unpublished data). He scored a 5 on the Blessed test ${ }^{6}$ because he was unable to recall the memory phrase. He scored within the superior to very superior range on all subtests of the WAIS. He easily solved all 12 items in set $A$ of the Ravens coloured progressive matrices, a test of spatial reasoning ability. His ability to copy line drawings was intact.

Verbal IQ remained stable until year 6; performance IQ declined a year earlier. An impairment in confrontation naming was noted in year 6 . At that time, cued recall on a 16 item list learned under controlled conditions ${ }^{7}$ was quite impaired.

Table Serial neuropsychological scores in years 1 to 7. $W A I S-P I Q=$ performance IQ from the Weschler Adult Intelligence Scale (WAIS). WAIS-VIQ= verbal IQ from the $W A I S . F O M E=$ score on recall 1 on the Fuld Object Memory Evaluation. Raven = score on set $A$ of the Raven coloured progressive matrices. Sum recall = recall on a 12item, 12-trial selective reminding test.

\begin{tabular}{lllllll}
\hline Year & Blessed & $\begin{array}{l}\text { WAIS } \\
P I Q\end{array}$ & $\begin{array}{l}\text { WAIS } \\
\text { VIQ }\end{array}$ & FOME & Raven & $\begin{array}{l}\text { Sum } \\
\text { Recall }\end{array}$ \\
\hline 1 & 5 & 140 & 134 & 4 & 12 & NA \\
2 & 5 & 141 & 134 & 3 & 12 & 24 \\
3 & 8 & 137 & 130 & 2 & 12 & 21 \\
4 & 10 & 124 & 128 & 0 & 12 & 23 \\
5 & 7 & 129 & 127 & 1 & 11 & 25 \\
6 & 8 & 124 & 118 & 2 & NA & 19 \\
7 & 10 & 113 & 103 & 2 & NA & NA \\
\hline
\end{tabular}

NA $=$ Not available. 
In years 5 and 6 he showed intact skill learning as measured by the speed of reading mirror reversed words. Nonrepeated words presented in session 2 were read faster than nonrepeated words presented in session $1(\mathrm{t}=3 \cdot 29, \mathrm{p}<0.01$, year $5 ; t=3.33, p<0.01$, year 6$)$. In contrast, he failed to show priming effects in reading words which were repeated across sessions. Words which were repeated in session 2 were not read faster than nonrepeated words in session $2(t=1 \cdot 26$, year $5 ; \mathrm{t}=0.68$, year 6). Recognition for both repeated and nonrepeated words were poor; the usual advantage for repeated words was not observed.

In year 5 his ability to recognise and play well known works of classical music was tested. The first two minutes of commercial recordings of six well known works were played on a cassette player. The patient was unable to recall the composer or title of any of the six works including the first movement of Beethoven's fifth symphony. Given a forced choice test with four alternatives per musical selection, he made one correct selection in six attempts. Next he was brought to the piano, and the examiner (HC) would play the first few bars of fifteen different pieces of popular classical music. In thirteen cases, the patient was able to continue playing the music as it had originally been written. He had, however, no idea of the composer of any of this music, nor could he select the correct composer on a forced choice test. Furthermore, if told the name of the composer, he could not identify the title of the music nor select it from a list of four possible titles.

In year 5, head CT, EEG, and routine blood studies for dementia evaluation were normal. He was diagnosed as having an amnesic disorder because he had no evidence of cognitive dysfunction other than memory impairment. Two years later, when intellectual functioning declined and impairment in confrontation naming became apparent, his diagnosis was changed to $\mathrm{AD}$. In year 8 , he could continue to play the passages on the piano but only for a few bars.

\section{Discussion}

Although there have been several previous demonstrations that neurological disease can dissociate declarative and procedural memory, ${ }^{189}$ our present case is the first to demonstrate that the dissociation occurs for both anterograde and retrograde memories. Impaired anterograde declarative memory was shown by his very poor scores on tests of free recall, cued recall, and recognition for new information. Impaired retrograde declarative memory was shown by an inability to recall or recognise previously learned classical compositions. In contrast, there was relative preservation of anterograde and retrograde procedural memory. Though unable to recall or recognise previously learned musical compositions, he could continue playing these compositions after cueing. However, cueing was not helpful in aiding retrieval of declarative memories. Relative preservation of anterograde procedural memory was demonstrated by his ability to acquire the skill of mirror reading.

This dissociation between procedural and declarative memory has been shown in other Alzheimer patients who could learn new procedures involving tapping, rotary pursuit, and pattern learning while showing no declarative memory for the new information. 9 Parkinson's disease produces the opposite pattern with subjects performing poorly on procedural memory tests, but well on declarative memory tests. ${ }^{9}$ Korsakoff and temporal lobectomy amnesic patients show a pattern of deficits similar to our subject. Huntington patients show a mixed pattern of deficits.'

Based on the pattern of dissociation caused by these different neurological diseases, the anatomical substrate of procedural memory is presumed to involve striato-prefrontal circuits, whereas the substrate of declarative memory is presumed to involve circuits connecting the hippocampus, subiculum, and association cortex. ${ }^{9}$ Much of the pathology in AD is found in these latter region $\mathrm{s}^{10}$ which is probably responsible for the impairment in declarative memory in AD patients. The skill of playing previously learned piano compositions from memory represents a special kind of procedural memory and is stored at least in part in the neostriatum, an area of the brain spared until the latest stages of $\mathrm{AD}$.

\section{References}

1 Squire L. Divisions of long term memory. In: Memor and Brain. New York: Oxford University Press, 1987, 151-74.

2 Fuld PA. The Fuld Object Memory Evaluation. Chicago Stoetling Instrument Co, 1981.

3 Fuld PA, Muramoto O, Blau AD, Westbrook L Katzman R. Cross cultural and multiethnic dementis evaluation by mental status testing. Cortex $1988 ;$ 24:511-9.

4 Masur DM, Fuld PA, Blau AD, Thal LJ, Levin HS, Aronson MK. Distinguishing normal and demented elderly with the selective reminding test. J Clin Exp Neuropsychol 1989;5:11.

5 Banks PG, Dickson AL, Plasay MT. The verbal selective reminding test: preliminary data for healthy elderly. Experimental Aging Research (1987) 13:203-7.

6 Fuld PA. Psychological testing in the differential diagnosis of the dementias. In: Katzman R, Terry RD, Biele KL, eds. Alzheimer's disease: senile dementia and related disorders. New York: Raven Press, 1978, 185-93.

7 Grober E, Buschke H, Crystal H, Bang S, Dresner R. Screening for dementia by memory testing. Neurology 1988;38:900-3.

8 Corkin S, Gabrielli JDE, Tanger BZ, et al. Skill learning and priming in Alzheimer's disease. Neurology 1986, 36(suppl 1):296.

9 Saint-Cyr JA, Taylor AE, Lang AE. Procedural learning and neostriatal dysfunction in man. Brain 1988, 111:941-59.

10 Tomlinson BE, Corsellis JAN. Ageing and the dementias In: Adams JH, Corsellis JAN, Duchen LW, eds. Greenfield's Neuropathology. New York: John Wiley and Son, 1984:951-1025. 